\title{
Application of Integrated Hardware and Software System "PRIZNAK-10M" for Measuring Power- Frequency Electric and Magnetic Fields in Electric Networks
}

\author{
Victor G. Kurbatsky, Energy System Institute
}

\begin{abstract}
One of the urgent problems in modern power industry is to provide safety of man staying in the affected area of electric and magnetic fields generated by operating electric facilities. The paper presents integrated hardware and software system "PRIZNAK-10M", intended for measurement of powerfrequency electric and magnetic fields in electric networks. Integrated hardware and software system put into practice the methods of measurements, met the regulatory documents effected in electric networks of Russia. The recommendations have been developed to provide the man safely at the facilities studied.
\end{abstract}

Keywords: integrated hardware and software system measurements of electric and magnetic fields

\section{INTRODUCTION}

Electric networks have a considerable adverse impact on the environment. There are a great number of various power facilities, which radiate electromagnetic fields thus deteriorating electromagnetic environment (EME). The intensity of electromagnetic fields (EMF) therewith currently exceeds the level of natural electric and magnetic fields of the Earth many times. First of all it sharpen the problems of electromagnetic compatibility among technical structures in energy sector and has an adverse impact on the health of people - bio-electromagnetic compatibility $[1,6]$. Currently the estimation of real effects of electric field (EF) and magnetic field (MF) near power facilities on technical facilities and man remains a challenging scientific and technical problem that requires a comprehensive study. This is caused by the complexity of electric connections and construction structures as well as configuration and operation of the studied electric network section.

\section{MEANS FOR MEASUREMENT OF POWER-FREQUENCY ELECTROMAGNETIC FIELDS IN ELECTRIC NETWORKS}

Electric networks create low-frequency electric and magnetic fields [1] which can be estimated by the intensity values of electric field, $\mathrm{E}, \mathrm{kV} / \mathrm{m}$ and $\mathrm{MF}, \mathrm{H}, \mathrm{A} / \mathrm{m}[1,2,3]$. Their maximum permissible levels of $\mathrm{EF}$ and $\mathrm{MF}$ are regulated by the Russian regulatory document [4] that makes it possible to secure the service staff while working in active electric facilities.
Generally the power-frequency EF and MF can be assessed by:

- Calculation methods;

- Direct measurements.

Therefore, it should be emphasized that the electromagnetic environment analysis is based on the methods of direct EMF measurements.

Tool-based analysis of EF and MF intensity should be made in accordance with the requirements [4], which establish the use of the devices intended for determination of effective $^{1}$ (root-mean-square) values of EF and MF intensities with a permissible relative error of $20 \%$ for electric and $10 \%$ for magnetic fields.

Most of the known methods intended for measurement of EF and MF levels [1] suggest the use of specialized information and measurement support (Fig. 1).

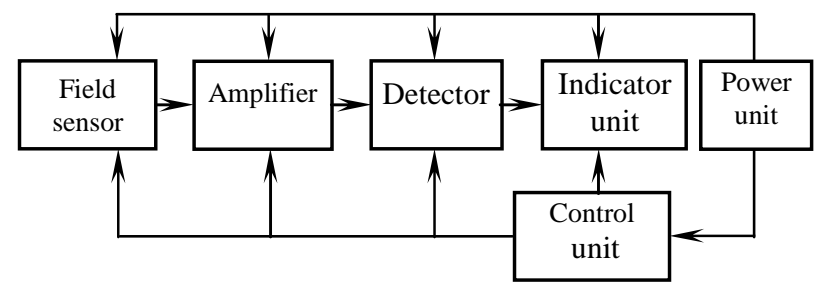

Fig.1. A standard block diagram of field intensity measuring systems.

Review of modern measurement devices (MD) intended to measure power-frequency EMF, that are included in the State register of measurement devices (Table 1), showed [6, 9] that these MD do not have the algorithms for automatic measurement of effective values of field intensity according to the requirements [4] that take into account the presence of elliptic nature fields.

It should be noted that the overwhelming majority of devices (Table 1) are the systems of directional reception, which have the algorithm for measurement of $\mathrm{EF}$ and $\mathrm{MF}$ intensity:

\footnotetext{
1 The effective value of intensity is taken to mean die effective value of a sinusoid with an amplitude equal to the semi-major axis of an ellipse or ellipsoid described by the vector of field intensity at a measurement point
} 
- directing anisotropic antenna, user defines orthogonal components of electric fields vector $\left(\mathrm{E}^{*}, \mathrm{E}_{\mathrm{Y}}, \mathrm{E}_{\mathrm{z}}\right)$ or magnetic fields vector $\left(\mathrm{H}_{\mathrm{x}}, \mathrm{H}_{\mathrm{Y}}, \mathrm{H}_{2}\right)$;

- resultant intensity value of $\mathrm{EF}, \mathrm{E}$ and $\mathrm{MF}, \mathrm{H}$ is defined with using formulae:

$$
\begin{aligned}
& E=\sqrt{E_{X}^{2}+E_{Y}^{2}+E_{Z}^{2}} \\
& H=\sqrt{H_{X}^{2}+H_{Y}^{2}+H_{Z}^{2}}
\end{aligned}
$$

Thus, while using MD intended for directional (anisotropic) reception, the possibility for correct measurement of effective intensity value of power-frequency $\mathrm{EF}$ and MF of elliptical nature is absent.

These fields occur, first of all, near three-phase electric facilities [7, 11], where vector of $\mathrm{EF}$ and $\mathrm{MF}$ intensity describes elliptic or ellipsoid curves. Their most typical shapes are shown in Fig. 2.
According to the standards [4] it is necessary' to measure effective value of a sinusoid with an amplitude equal to a semi-major axis of ellipse described by vector $\mathrm{E}$ or $\mathrm{H}$ at a given point. In this case the values measured by the existing devices (Table 1) exceed real ones (Fig. 2). As this takes place, the closer the ellipses form to circumference - the higher the measurement error.

The calculations show that the maximum measurement error makes up $41 \%$.

A way of solving the problem of determining the effective intensity value of power-frequency EF or MF is using the method, which exploits the expressions:

TABLE 1

POWER-FREQUENCY EF AND MF MEASURING DEVICES INCLUDED IN THE STATE REGISTER (AS OF 2009)

\begin{tabular}{|c|c|c|c|c|c|}
\hline Measuring device type & $\begin{array}{c}\text { № of certificate in } \\
\text { State register }\end{array}$ & Frequency range & Measurement range & Antenna type & Error value \\
\hline ПЗ-50В & $17638-98$ & $48 \div 52 \mathrm{~Hz}$ & $0.01 \div 180 \mathrm{kV} / \mathrm{m}$ & Directional & $\pm 15 \%$ \\
& $17288-98$ & $5 \mathrm{~Hz} \div 2 \mathrm{k} \mathrm{Hz}$ & $10 \div 200 \mathrm{~V} / \mathrm{m}$ & Directional & $\pm 20 \%$ \\
\hline ИЭП-05 & $17289-98$ & $5 \mathrm{~Hz} \div 2 \mathrm{k} \mathrm{Hz}$ & $100 \div 2000 \mathrm{nT}$ & Directional & $\pm 20 \%$ \\
\hline ИМП-05 & $17287-98$ & $5 \mathrm{~Hz} \div 2 \mathrm{k} \mathrm{Hz}$ & $7 \div 1000 \mathrm{~V} / \mathrm{m}$ & Directional & $\pm 10 \%$ \\
\hline ИЭП-04 & $15527-96$ & $5 \mathrm{~Hz} \div 2 \mathrm{k} \mathrm{Hz}$ & $200 \div 5000 \mathrm{nT}$ & Directional & $\pm 10 \%$ \\
\hline ИМП-04 & $16372-97$ & $40 \div 200 \mathrm{~Hz}$ & $0.01 \div 199.9 \mathrm{mT}$ & Directional & $\pm 2.5 \% ; \pm 5 \%$ \\
\hline МПМ-2 & $17396-98$ & $5 \div 2000 \mathrm{~Hz}$ & $8 \div 100 \mathrm{~V} / \mathrm{m}$ & Directional & $\pm 20 \%$ \\
\hline ВЕ-МЕТР-АТ-002 & & & & $0.08 \div 1 \mu \mathrm{T}$ & \\
\hline
\end{tabular}

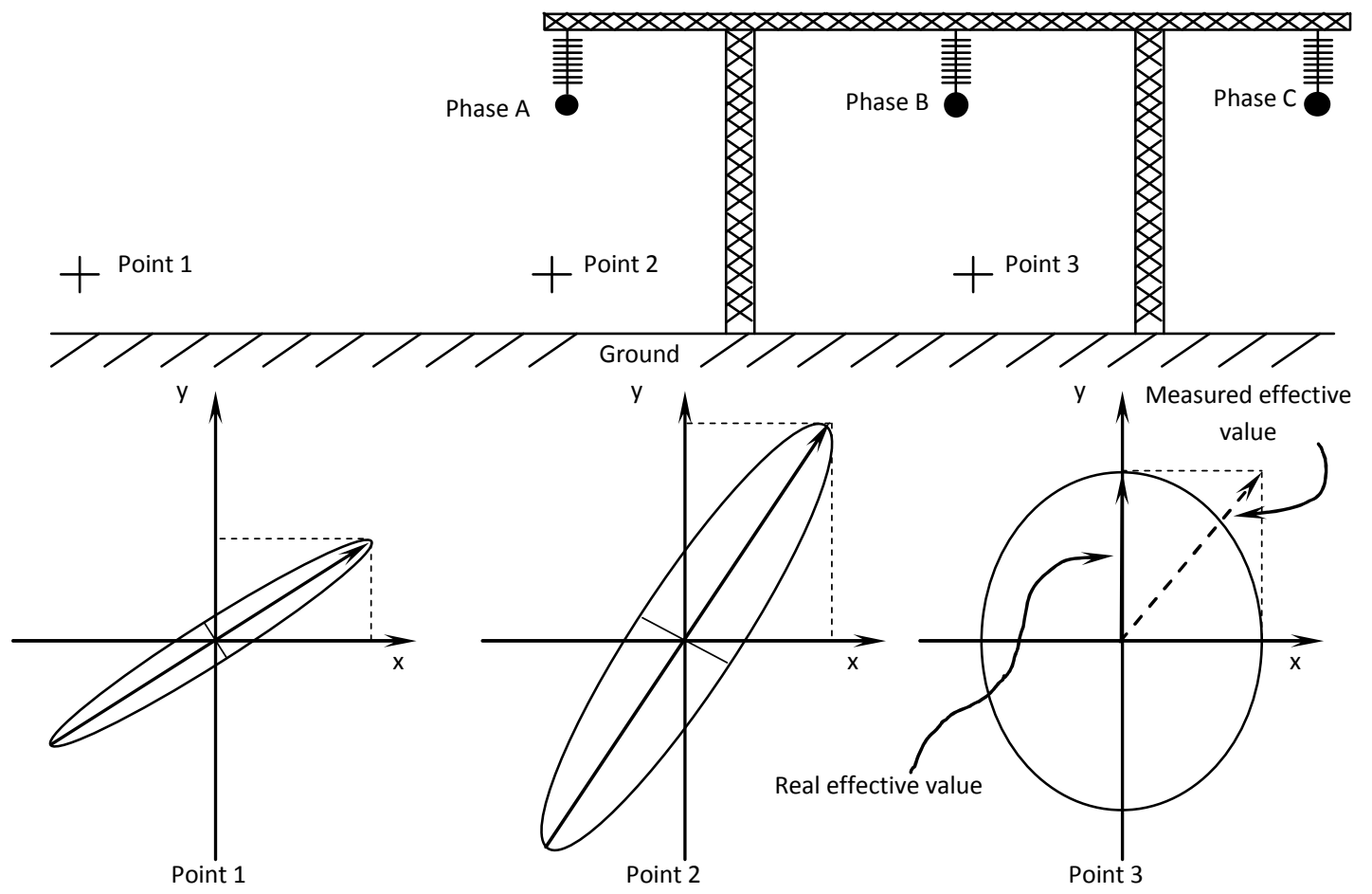

Fig.2. Location of measurement points of MF near transmission line and elliptic curves described by the vector $\mathrm{H}$ at these points 


$$
E=\frac{\sqrt{\max \left|E(t)_{X}^{2}+E(t)_{Y}^{2}+E(t)_{Z}^{2}\right|}}{\sqrt{2}}
$$

where $E(t)_{X} ; E(t)_{Y} ; E(t)_{Z}$ - instantaneous values of $\mathrm{EF}$ intensity, respectively, that are measured by the threecoordinate field sensor at any spatial orientation of measurement system.

\section{INTEGRATED HARDWARE AND SOFTWARE SYSTEM \\ "PRIZNAK-10M" FOR MEASURING POWER-FREQUENCY ELECTRIC AND MAGNETIC FIELDS IN ELECTRIC NETWORKS}

To solve the problem of EF and MF of elliptic polarization the integrated hardware and software system (IHSS) "PRIZNAK-10M" [5, 8, 10, 11] (Fig.4, 5) was developed. It meets the standards [4] and has the following characteristics:

- Measures effective value of the sinusoid with the amplitude equal to the semimajor axis of ellipse (ellipsoid) described by the vector of EF and MF at a given point of space.
- Has a non-directional (anisotropic) antenna that makes the calculation results independent of spatial orientation of the device.

- Measures $50 \mathrm{~Hz}$ power-frequency EMF intensity regulated by the current standards for electric networks in Russia.

- Uses automatic procedure of measuring EF and MF intensities, thus excluding involvement of an operator.

- Does not distort the existing picture of EF and MF at a measurement point.

- Processes measurement results by microcontrollers.

- Has small sizes and a comfortable interface.

Integrated hardware and software system "PRIZNAK$10 \mathrm{M}$ " consists of two main parts connected by means of optical communication. (Fig. 4):

- Measurement Probe (MP) of electric and magnetic fields;

- $\quad$ Interface Module (IM).

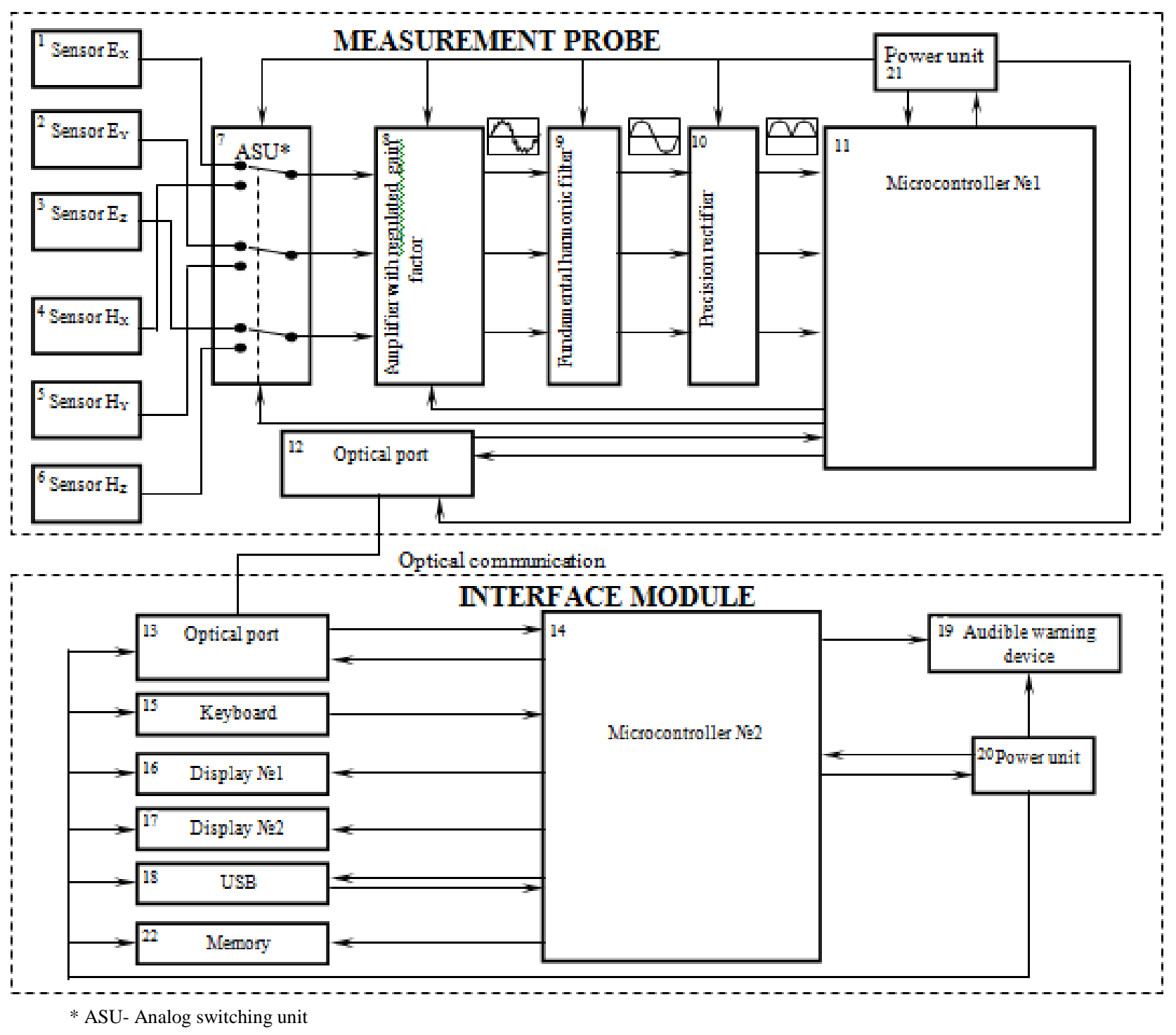

Fig.3. A block diagram of the IHSS for measuring power -frequency EF and MF intensity 
TABLE II

BASIC TECHNICAL FEATURES OF 1HSS "PR1ZNAK-10M"

\begin{tabular}{|c|c|c|}
\hline Parameter & Quantity & $\begin{array}{c}\text { Measurement } \\
\text { Units }\end{array}$ \\
\hline $\begin{array}{c}\text { Measurement Range of Electric Field } \\
\text { Intensity }\end{array}$ & $0,001+100$ & $\mathrm{kV} / \mathrm{m}$ \\
\hline $\begin{array}{c}\text { Measurement Range of Magnetic Field } \\
\text { Intensity }\end{array}$ & $0,1+10000$ & $\mathrm{~A} / \mathrm{m}$ \\
\hline Basic and Relative Error Value & \pm 5 & $\%$ \\
\hline Quantity of Limits of Effective Range & 3 & $\mathrm{~mm}$ \\
\hline Volume of Nonvolatile Memory & 2032 & $\mathrm{of} \mathrm{values}$ \\
\hline Dimension of Device & $570 \times 95 \times 95$ & $\mathrm{mg}$ \\
\hline Weight & 0,39 & \\
\hline
\end{tabular}

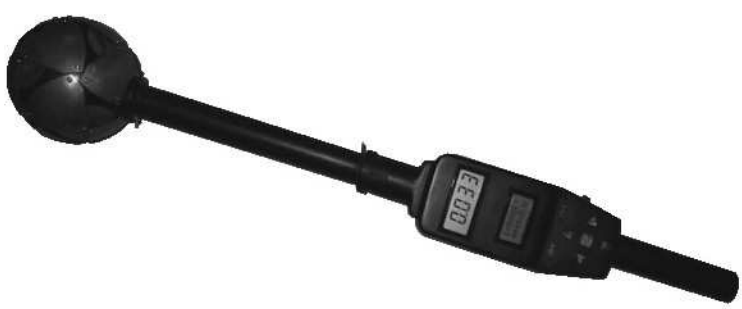

since such switchgears are not practically equipped with stationary devices for staff protection from EF.

The experimental estimation of EME at the cutest of the $500 \mathrm{kV}$ switchgear at the Bratsk HPP (Fig. 10) reveals high EF intensity levels [8]. This fact is explained first of all by compact arrangement of electric facilities. And the maximum value of EF intensity equal to $22.5 \mathrm{kV} / \mathrm{m}$ was registered near the crosspoint of phase A of TL 571 and the phase A of the flexible system of busbars of the $500 \mathrm{kV}$ switchgear. The maximum value of MF intensity at the time of taking measures did not exceed the maximum permissible value equal to $80 \mathrm{~A} / \mathrm{m}$ and amounted to $32 \mathrm{~A} / \mathrm{m}$. Note that it is difficult to calculate the maximum field values at switchgears by expressions $(5,6)$ because of complex configuration of electric facilities.

Blocks $1-3$ and 4-6 are anisotropic sensors of EF and MF. Signals from these blocks arrive at amplifier with regulated gain factor (Block 8) via analog switching unit (ASU) (Block 7).

Fig.4. External view of the IHSS «PRIZNAK -10M»

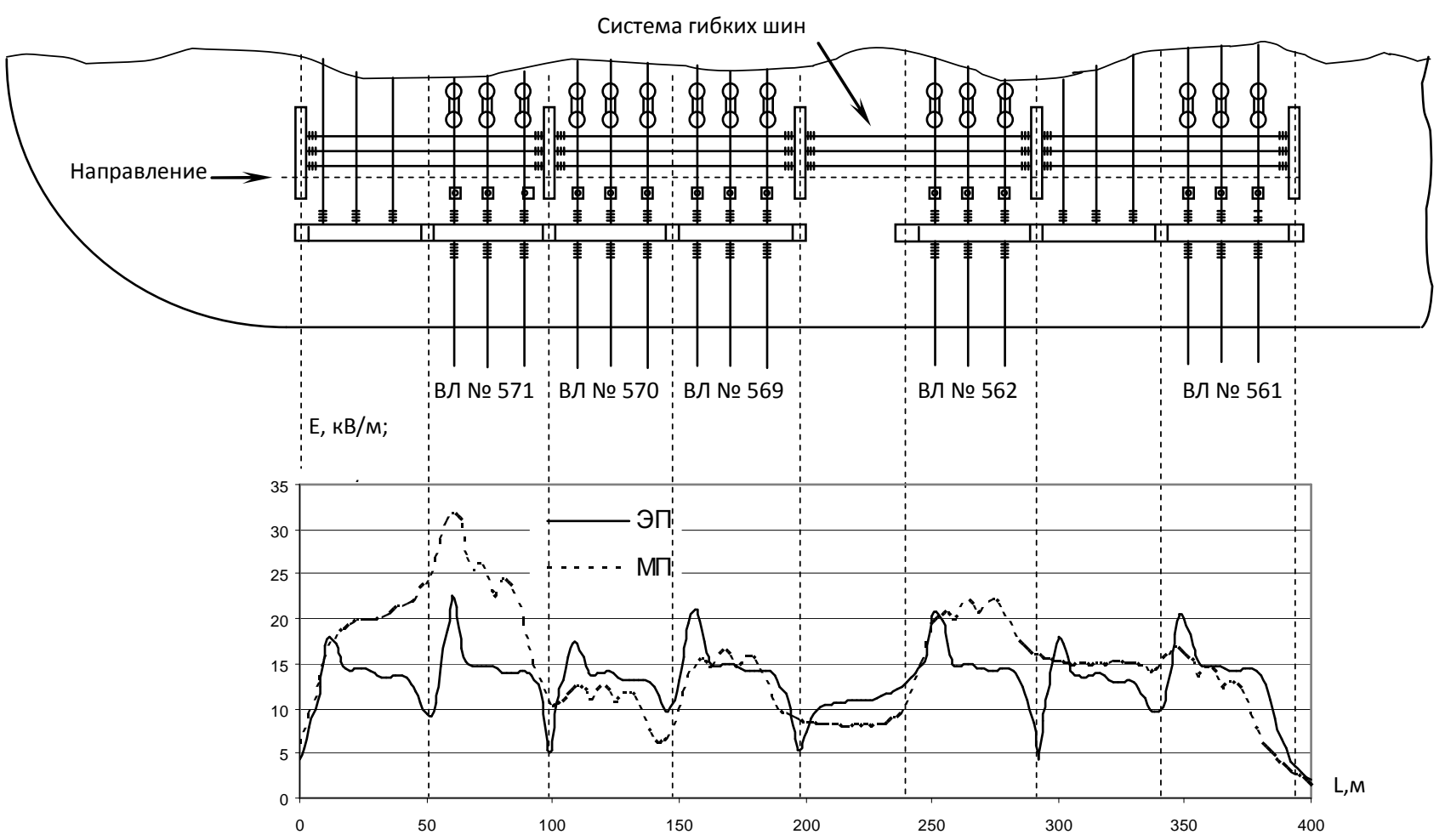

Fig. 5. Results of measuring power-frequency EF and MF intensity at the cutest of $500 \mathrm{kV}$ switchgear at the Bratsk HPP.

- EME at the outdoor switchgear of power plants.

From the standpoint of negative impact on man the outdoor switchgears of power plants are most unfavorable components of electric networks. As regards bioelectromagnetic compatibility, the service staff of the outdoor switchgears $220 \div 500 \mathrm{kV}$ runs into the most serious danger,
There is amplifier-multiplexer in block 8 , which realizes switching of the gain factor (limit of effective range) by means of a command from microcontroller №1 (Block 11). Then amplified in block 8, signals arrive at precision rectifier (Block 10) via fundamental harmonic filter (Block 9). The amplified, filtered and rectified signal from block 10 output, goes to analog input of microcontroller № 1 (Block 11). Signals transformation into digital form and mathematical treatment of 
them are put into practice in microcontroller №2 in compliance with the expressions (7) and (8). The signal thereafter arrives at microcontroller №2 (block 14) via optical ports (blocks 12 and 13) for storage and visualization (blocks 16, 17, 19 and 22). IM is provided with a serial USB port (block 18) for transmitting data to IBM-compatible computer. Both parts of the device - MP and IM - have independent power sources (blocks 21 and 22 respectively).

The IHSS "PRIZNAK.-10M" has been currently used for large-scale experimental studies of the EME. The experiments have proved the system to be highly efficient in solving the problems of operating control of $\mathrm{EF}$ and $\mathrm{MF}$ in real electric networks of Russia [8].

The values of EF intensity inside the switchgear of generating voltage were practically equal to zero, since the current-carrying components were closed by metal structures screening EF.

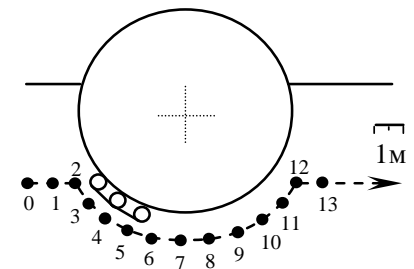

Fig.6. Schematic spacing of measurement points close to the $250 \mathrm{MW}$ hydroelectric generator (top view).

- EME in the switchgear of generating voltage of power plants.

In the course of measurements of MF intensity in the generator hall of the Bratsk HPP that were performed at the level of stator neutral outputs (Fig. 6), at the height $1 \mathrm{~m}$ from the floor level, the maximum value of MF intensity was 1590 $\mathrm{A} / \mathrm{m}$ at the stator current $7.5 \mathrm{kA}$ (Fig. 7). However, at $4 \mathrm{~m}$ from the generator the value of MF intensity was not higher than the value of the maximum permissible level equal to 80 $\mathrm{A} / \mathrm{m}$.

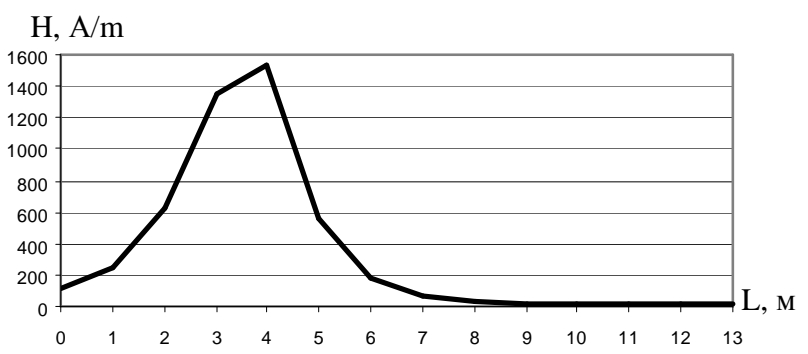

Fig. 7. Results of measuring MF intensity near the hydroelectric generator $(\mathrm{A} / \mathrm{m})$.

\section{IV.PROTECTION OF SERVICE STAFF SURING WORKS IN ELECTRIC NETWORKS.}

In general the bio-electromagnetic compatibility in electric networks in the zones of increased effect of electric and magnetic fields is provided for by a series of organizational and technical measures $[1,4]$ :
- Limitation of time for service staff stay in the zones of higher levels of fields in accordance with the requirements.

- Use of special screening suits at the EF intensity above $25 \mathrm{kV} / \mathrm{m}$.

- Arrangement of EF-screening structures, such as cable screens, protective screening deflectors, etc. [1].

- Planning of works for the time of minimum current modes of electric facilities.

However, implementation of the whole set of protective actions proves to be expensive and not always efficient. Besides, specific features of the studied electric networks in Siberia and the Far East do not allow the set of protective measures to be provided, since the studied objects differ in the levels of affecting EF and MF that essentially vary over time. Therefore, each studied object requires utilization of a set of individual measures most efficient from the standpoint of bioelectromagnetic compatibility provision.

A. Measures on service staff protection from EMF of transmission lines.

Since in the studied corridor of TLs the levels of powerfrequency MF intensity during maximum loads did not exceed the standard-regulated MPL $80 \mathrm{~A} / \mathrm{m}$ [4] at relatively high EF values up to $8.2 \mathrm{kV} / \mathrm{m}$, the principal measure on the service staff protection consists in limitation of time for the service staff stay in these conditions. According to (1) the permissible time of stay was 4.1 hours under TL $500 \mathrm{kV}$. Under TL 220 $\mathrm{kV}$ the maximum levels of EF intensity did not exceed MPL of $5 \mathrm{kV} / \mathrm{m}$, hence the time of stay under such TLs may be unlimited.

Note that utilization of different stationary screening structures is not economically sound because of great length of TLs 220 and $500 \mathrm{kV}$. The screening suits of Russian manufacture may also be used under TLs $500 \mathrm{kV}$, however, they considerably decrease effectiveness of staff work.

\section{B. Measures on service staff protection from EMF of the outdoor switchgears of power plants.}

As is shown in Fig 10, the maximum value of EF intensity at the cutest of outdoor switchgear makes up $22.5 \mathrm{kV} / \mathrm{m}$, which corresponds to the permissible time of stay for $10 \mathrm{~min}$. Therefore, the service staff cannot practically work in such conditions without screening suits. Besides, portable and stationary screening structures installed in the places, where works are performed, can also be successfully used at the outdoor switchgears. Because of sufficient difficult to forecast the maximum levels of power-frequency MF at the outdoor switchgears now, it is appropriate to give an expert estimate of MF levels in advance to specify the real EME by using, for example, the integrated hardware and software system "PRIZNAK-10M".

C. Measures on service staff protection from EMF in the switchgears of generating voltage.

As was shown earlier, the magnetic field is the principal influencing factor in the indoor switchgears of generating voltage. In this case heavy currents of electric equipment can 
stipulate high MF values. Since MFs are not practically screened, the measures on limitation of time for the service staff stay prove to be inefficient. Performance of works during minimal current loads, such as transfer of generators to idling or synchronous compensation can be considered as a certain way out.

\section{Measures on man protection at objects of municipal and domestic sector.}

In the case of higher background of power-frequency EF in the premises of residential and municipal buildings the protective PEN conductor of electric network can be used for screening [1]. This measure decreases the power-frequency EF level in the premise by several times (Fig. 8).

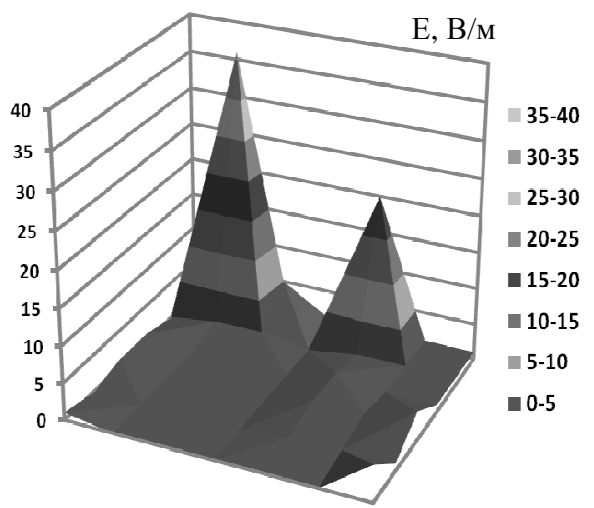

Fig. 8. Map of distribution of power-frequency EF intensity in the premise of municipal sector after taking measures on EF screening (V/m).

On the whole, the application of methods for powerfrequency EF screening in the municipal and domestic sector is the cheapest and effective measure.

\section{CONCLUSIONS}

The paper presents integrated hardware and software system "PRIZNAK-10M", intended for measurement of power-frequency electric and magnetic fields in electric networks. Integrated hardware and software system put into practice the methods of measurements, met the regulatory documents effected in electric networks of Russia. The recommendations have been developed to provide the man safely at the facilities studied.

The effective methods for man protection from the impact of electric and magnetic fields are suggested for the examined objects.

\section{ACKNOWLEDGMENT}

The study was supported by the Grants of Leading Scientific of RF\#4633.2010.8 and Russian Foundation of Basic Researches \#09-08-91330 and Federal Agency for Science and Innovations within Federal Program "R\&D in Priory Areas of Russia's Science and Technological Complex Development for 2007-2012"

\section{REFERENCES}

[1] A.F. Diakov, Electromagnetic compatibility in electric power industry and electrical engineering. M.: Energoatomizdat, 2003. - 768 p. (in Russian)

[2] E. Khabiger, Electromagnetic compatibility. Fundamentals of its provision in engineering. M.: Energoatomizdat, 1995. - 343 p. (in Russian)

[3] Schwab A. Electromagnetic compatibility. Translated from German by V.D.Mazin and S.A.Spektor. $2^{\text {nd }}$ edition, revised and supplemented/ Ed. by Kuzhekin I.P. M.: Energoatomizdat, 1998. -480 p. (in Russian)

[4] SanPin 2.2.4.1191-03. Electromagnetic fields in working environment. - M.: Izdatelstvo NTs ENAS, 2003. - 24 p. (in Russian)

[5] V.G.Kurbatsky, A.V.Strumelyak, "Device for measuring electric and magnetic field intensity," Patent of RF No.44832. (in Russian)

[6] V.G. Kurbatsky, "Measurement support to estimate electromagnetic effects at operation of high-voltage transmission lines," Power system: control, quality security. Collected papers of the Russian scientific and technical conference. Ekaterinburg: UGTU-UPI, 2001. - P. 304-306. (in Russian)

[7] V.G. Kurbatsky, "Tool-based express-estimation of powerfrequency electric and magnetic field intensity," V.G.Kurbatsky, A.V.Strumelyak, Collected papers of the $10^{\text {th }}$ Russian scientific and technical conference on electromagnetic compatibility of technological tools and electromagnetic security "EMS"-2008". St.Petersburg: VITU, 2008. (in Russian)

[8] Kurbatsky V.G. Study on electromagnetic environment at objects of electric power industry and municipal sector / V.G Kurbatsky, A.V.Strumelyak, Elektrika, No.11. - 2006. - P.29-37. (in Russian)

[9] Kurbatsky V.G. Instruments for estimation of electromagnetic environment at objects of electric power industry, V.G.Kurbatsky, A.V.Strumelyak, Promyshlennaya energetika, No. 8. - 2006. - P.12-17. (in Russian)

[10] V.G. Kurbatsky, "Universal integrated hardware and software system "PRIZNAK-10M" for measuring electric and magnetic field intensity," V.G.Kurbatsky, A.V.Stumelyak, Energetik, No.5. - 2007. - P.29-30. (in Russian)

[11] A.V. Strumelyak, "Universal integrated hardware and software system "PRIZNAK-10M" for measuring electric and magnetic field intensity," Tekhnologii EMS, No.2(9), 2004. - P. 40-44. (in Russian)

Victor G. Kurbatsky.

Leading researcher, IEEE member

Energy Systems Institute,

Siberian Branch of Russian Academy of Sciences, Irkutsk, Russia.

E-mail: kurbatsky@isem.sei.irk.ru 